\title{
General Aspects of the Glycosidic Bond Formation
}

Alexei V. Demchenko

\section{1}

Introduction

Since the first attempts at the turn of the twentieth century, enormous progress has been made in the area of the chemical synthesis of $O$-glycosides. However, it was only in the past two decades that the scientific world had witnessed a dramatic improvement the methods used for chemical glycosylation. The development of new classes of glycosyl donors has not only allowed accessing novel types of glycosidic linkages but also led to the discovery of rapid and convergent strategies for expeditious oligosaccharide synthesis. This chapter summarizes major principles of the glycosidic bond formation and strategies to obtain certain classes of compounds, ranging from glycosides of uncommon sugars to complex oligosaccharide sequences.

\section{2}

\section{Major Types of O-Clycosidic Linkages}

There are two major types of $O$-glycosides, which are, depending on nomenclature, most commonly defined as $\alpha$ - and $\beta$-, or 1,2-cis and 1,2-trans glycosides. The 1,2-cis glycosyl residues, $\alpha$-glycosides for D-glucose, D-galactose, L-fucose, D-xylose or $\beta$-glycosides for D-mannose, L-arabinose, as well as their 1,2-trans counterparts ( $\beta$-glycosides for D-glucose, D-galactose, $\alpha$-glycosides for D-mannose, etc.), are equally important components in a variety of natural compounds. Representative examples of common glycosides are shown in Figure 1.1. Some other types of glycosides, in particular 2-deoxyglycosides and sialosides, can be defined neither as 1,2-cis nor as 1,2-trans derivatives, yet are important targets because of their common occurrence as components of many classes of natural glycostructures. 


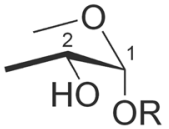

1,2-cis<smiles>[R]OC1OC(CO)C(O)C(O)C1O</smiles>

$\alpha-D-G a l a c t o-$ pyranoside<smiles>[R]OC1OC(C)C(O)C(O)C1O</smiles>

$\alpha-L-F u c o-$ pyranoside<smiles>[R]OC(O)[C@H]1C(O)C(O)C[C@@H]1CO</smiles>

$\beta$-D-Mannopyranoside

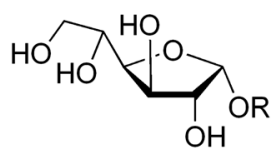

$\alpha-D-G l u c o-$ furanoside

$\mathrm{R}$ = generic aglycone residue

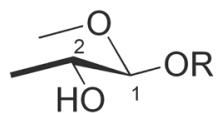

1,2-trans

Neither 1,2-cis nor 1,2-trans (common names are given)

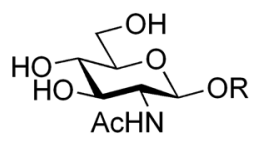

2-Acetamido-2-deoxy$\beta$-D-glucopyranoside<smiles>[R]OC1C(O)OCC(O)C1O</smiles>

$\beta$-D-Xylopyranoside<smiles>[R]C1O[C@H](CO)[C@H](O)C1O</smiles>

$\alpha-D-A r a b i n o-$ furanoside
$\beta$-D-Gluco-
pyranoside<smiles>[R]OC1CC(O)C(O)CC1(O)CO</smiles>

2-Deoxy- $\beta$-Dglucopyranoside

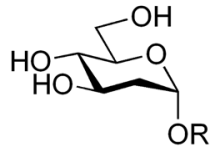

2-Deoxy- $\alpha$-Dglucopyranoside

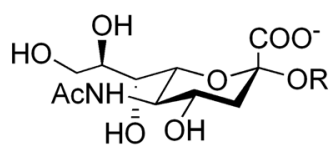

$\alpha$-Sialoside

Figure 1.1 Common examples of O-glycosides.

\section{3}

\section{Historical Development: Classes of Glycosyl Donors}

The first reactions performed by Michael (synthesis of aryl glycosides from glycosyl halides) [1] and Fischer (synthesis of alkyl glycosides from hemiacetals) [2] at the end of the nineteenth century showed the complexity of the glycosylation process. The discovery of the first controlled, general glycosylation procedure involving the nucleophilic displacement of chlorine or bromine at the anomeric center is credited to Koenigs and Knorr [3]. The glycosylations were performed in the presence of $\mathrm{Ag}_{2} \mathrm{CO}_{3}$, which primarily acted as an acid $(\mathrm{HCl}$ or $\mathrm{HBr})$ scavenger. At that early stage, glycosylations of poorly nucleophilic acceptors such as sugar hydroxyls were sluggish and inefficient; hence, even the synthesis of disaccharides represented a notable challenge. The first attempts to solve this problem gave rise to the development of new catalytic systems that were thought to be actively involved in the glycosylation process [4]. Thus, Zemplen and Gerecs [5] and, subsequently, Helferich and Wedermeyer [6] assumed that the complexation of the anomeric bromides or chlorides with more reactive, heavy-metal-based catalysts would significantly improve their leaving-group ability. This approach that has become a valuable expansion of the classic Koenigs-Knorr method made it possible to replace $\mathrm{Ag}_{2} \mathrm{CO}_{3}$ or $\mathrm{Ag}_{2} \mathrm{O}$ by more active mercury(II) salt catalysts. The early attempts 
to improve the glycosylation process have revealed the necessity to find a delicate balance between the reactivity and stereoselectivity [7,8]. Indeed, it was noted that faster reactions often result in a decreased stereoselectivity. At around the same time, the first attempts to involve other classes of anomeric leaving groups (LGs) resulted in the investigation of peracetates as glycosyl donors [9].

Seminal work of Lemieux [10] and Fletcher and coworkers [11,12] has led to the appreciation that the reactivity of the glycosyl halides and the stereoselectivity of glycosylation are directly correlated to the nature of the protecting groups, especially at the neighboring C-2 position. From early days, it has been acknowledged that peracylated halides often allow stereoselective formation of 1,2-trans glycosides. Later, this phenomenon was rationalized by the so-called participatory effect of the neighboring acyl substituent at C-2. Although occasionally substantial amounts of 1,2-cis glycosides were obtained even with 2-acylated glycosyl donors, the purposeful 1,2-cis glycosylations were best achieved with a nonparticipating ether group at C-2, such as methyl or benzyl. Further search for suitable promoters for the activation of glycosyl halides led to the discovery of Ag-silicate that proved to be very efficient for direct $\beta$-mannosylation, as these reactions often proceed via a concerted $\mathrm{S}_{\mathrm{N}} 2$ mechanism [13,14].

For many decades classic methods, in which anomeric bromides, chlorides, acetates or hemiacetals were used as glycosyl donors, had been the only procedure for the synthesis of a variety of synthetic targets ranging from simple glycosides to relatively complex oligosaccharides (Figure 1.2). Deeper understanding of the reaction mechanism, driving forces and principles of glycosylation have stimulated the development of other methods for glycosylation, with the main effort focusing on the development of new anomeric leaving groups $[15,16]$. During the 1970 s to early 1980 s, a few new classes of glycosyl donors were developed. The following compounds are only the most representative examples of the first wave of the leaving-group development: thioglycosides by Ferrier et al. [17], Nicolaou et al. [18], Garegg et al. [19] and others [20]; cyanoethylidene and orthoester derivatives by Kochetkov and coworkers [21,22]; O-imidates by Sinay and coworkers [23] and Schmidt and Michel [24]; thioimidates including S-benzothiazolyl derivatives by Mukaiyama et al. [25]; thiopyridyl derivatives by Hanessian et al. [26] and Woodward et al. [27] and glycosyl fluorides by Mukaiyama et al. [28] (Figure 1.2). Many glycosyl donors introduced during that period gave rise to excellent complimentary glycosylation methodologies. Arguably, trichloroacetimidates [29,30], thioglycosides [31-33] and fluorides [34,35] have become the most common glycosyl donors nowadays.

A new wave of methods arose in the end of the 1980s, among which were glycosyl donors such as glycosyl acyl/carbonates [36-38], thiocyanates [39], diazirines [40], xanthates [41], glycals [42,43], phosphites [44,45], sulfoxides [46], sulfones [47], selenium glycosides [48], alkenyl glycosides [49-51] and heteroaryl glycosides [52] (Figure 1.2). These developments were followed by a variety of more recent methodologies and improvements, among which are glycosyl iodides [53], phosphates [54], Te-glycosides [55], sulfonylcarbamates [56], disulfides [57], 2-(hydroxycarbonyl) benzyl glycosides [58] and novel thio- $[59,60]$ and O-imidates $[61,62]$ (Figure 1.2). In 
Classic methods early 1900 1960s

Methods from mid-1970s to early 1980 s
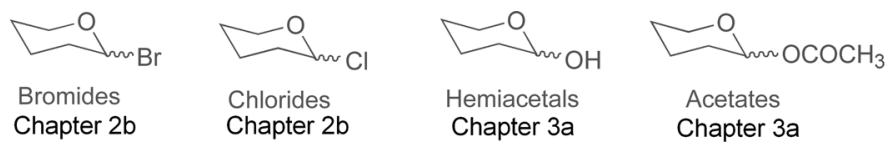

Chapter $3 a$

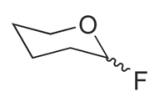

Fluorides Chapter $2 a$<smiles>[R]C(=[V])O[C@H]1CCCO1</smiles>

O-Imidates Chapter $3 \mathrm{~b}$<smiles>[R9]C1CCCO1</smiles>

S-Alkyl/Aryl Chapter $4 a$
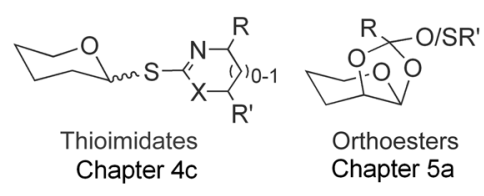

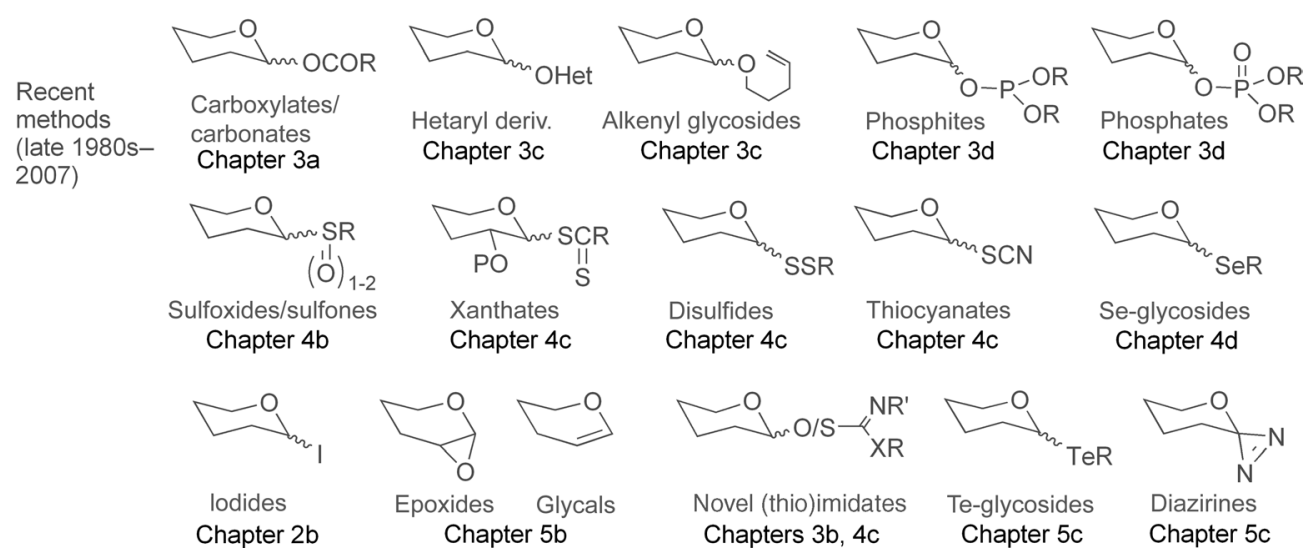

Figure 1.2 Survey of glycosyl donors.

addition, a variety of new recent methodologies bring the use of classic glycosyl donors such as hemiacetals to entirely different level of flexibility and usefulness [63]. These innovative concepts will be discussed in the subsequent chapters dealing with particular classes of clycosyl donors..

\section{4}

\section{General Reaction Mechanism}

Detailed glycosylation mechanism has not been elucidated as yet; therefore, speculations and diagrams presented herein are a commonly accepted prototype of the glycosylation mechanism. Most commonly, the glycosylation reaction involves nucleophilic displacement at the anomeric center. As the reaction takes place at the secondary carbon atom with the use of weak nucleophiles (sugar acceptors), it often follows a unimolecular $\mathrm{S}_{\mathrm{N}} 1$ mechanism. Glycosyl donors bearing a nonparticipating and a participating group will be discussed separately (Scheme 1.1a and b, respectively). In most cases, an activator (promoter or catalyst) assisted departure of the anomeric leaving group results in the formation of the glycosyl cation. The only 
1.4 General Reaction Mechanism |5

(a)

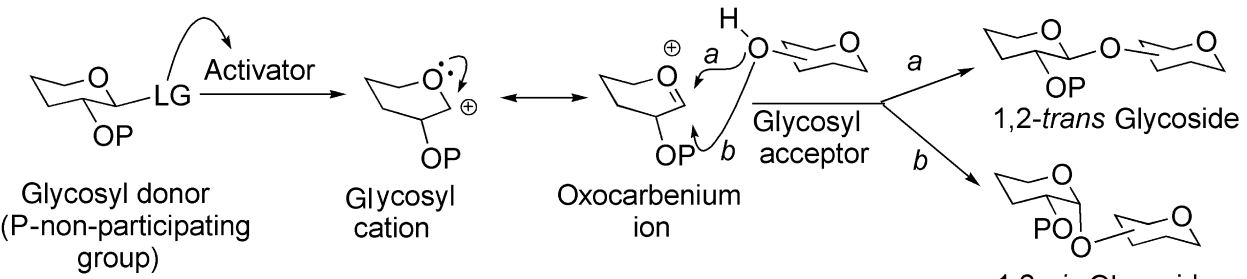

1,2-cis Glycoside main product (anomeric effect)

(b)

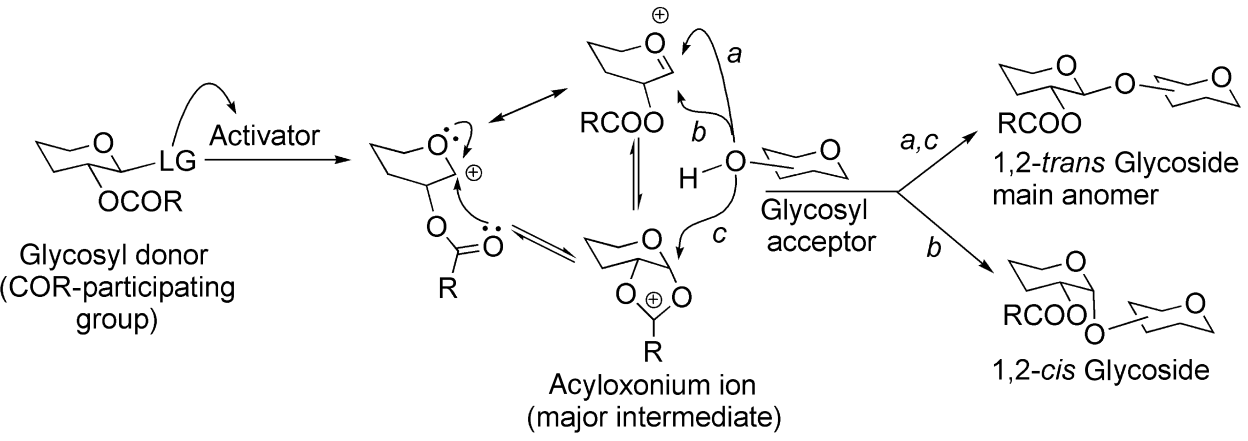

\section{Scheme 1.1}

possibility to intramolecularly stabilize glycosyl cation formed from the glycosyl donor bearing a non-participating group is by resonance from O-5 that results in oxocarbenium ion (Scheme 1.1a). The most commonly applied nonparticipating groups are benzyl $(\mathrm{OBn})$ for neutral sugars and azide $\left(\mathrm{N}_{3}\right)$ for 2-amino-2-deoxy sugars; however, other moieties have also been occasionally used. The anomeric carbon of either resonance contributors is $\mathrm{sp}^{2}$ hybridized; hence, the nucleophilic attack would be almost equally possible from either the top (trans, $\beta$ - for the D-gluco series) or the bottom face (cis, $\alpha$-) of the ring. Even though the $\alpha$-product is thermodynamically favored because of the so-called anomeric effect (discussed in the subsequent section) [64], a substantial amount of the kinetic $\beta$-linked product is often obtained owing to the irreversible character of glycosylation of complex aglycones. Various factors such as temperature, protecting groups, conformation, solvent, promoter, steric hindrance or leaving groups may influence the glycosylation outcome (discussed below) [65,66].

1,2-trans Glycosidic linkage can be stereoselectively formed with the use of anchimeric assistance of a neighboring participating group, generally an acyl moiety such as O-acetyl (Ac), O-benzoyl (Bz), 2-phthalimido (NPhth) and so on [67-69]. These glycosylations proceed primarily via a bicyclic intermediate, the acyloxonium ion (Scheme 1.1b), formed as a result of the activator-assisted departure of the leaving group followed by the intramolecular stabilization of the glycosyl cation. In this case, the attack of a nucleophile (alcohol, glycosyl acceptor) is only possible from the top face of the ring (pathway c), therefore allowing stereoselective formation of a 1,2-trans glycoside. Occasionally, substantial amounts of 1,2-cis-linked products are also 


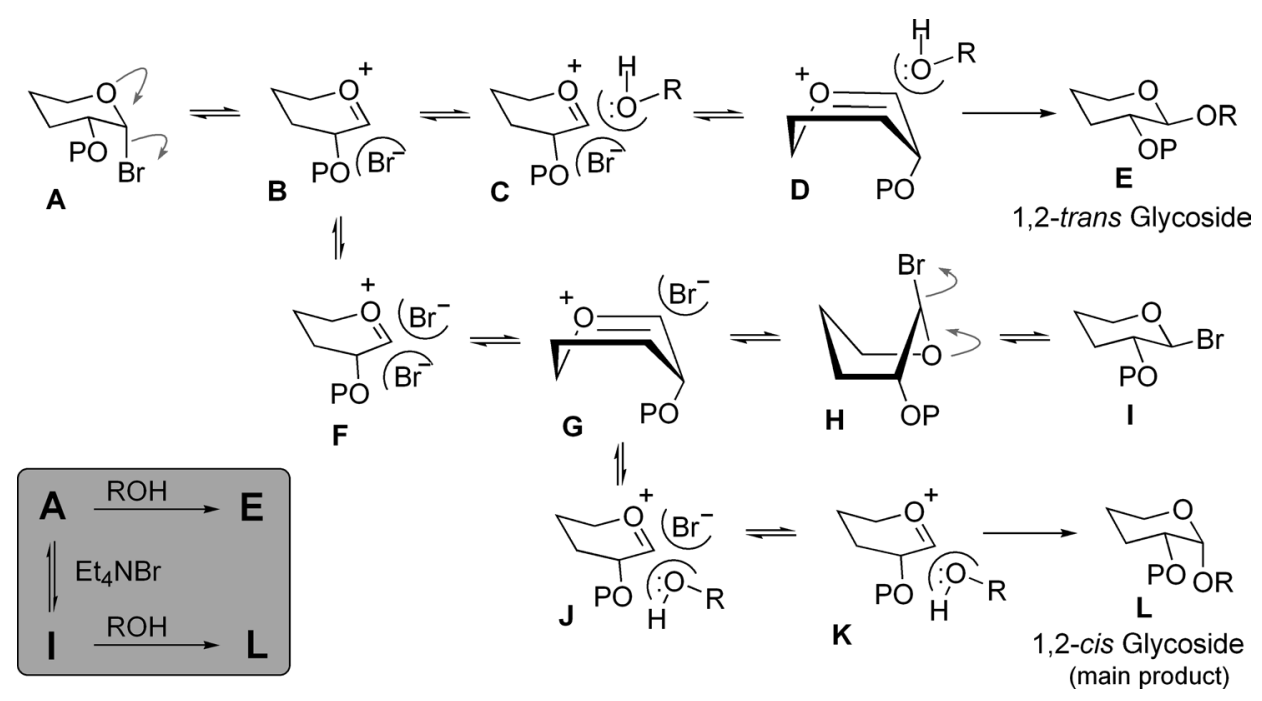

Scheme 1.2

formed, most often when unreactive alcohols are used as the substrates and/or poorly nucleophilic participatory substituents are present at C-2. In these cases, glycosylation assumingly proceeds via oxocarbenium ion, via pathways a and $\mathrm{b}$ (Scheme 1.1b), resulting in the formation of 1,2-trans and 1,2-cis glycosides, respectively, or most commonly mixtures thereof.

Seminal work by Lemieux on the halide-ion-catalyzed glycosidation reaction involved extensive theoretical studies that gave rise to a more detailed understanding of the reaction mechanism [70]. Thus, it was postulated that a rapid equilibrium could be established between a relatively stable $\alpha$-halide $\mathbf{A}$ and its far more reactive $\beta$-counterpart $\mathbf{I}$ by the addition of tetraalkylammonium bromide $\left(\mathrm{Et}_{4} \mathrm{NBr}\right.$, Scheme 1.2). In this case, a glycosyl acceptor $(\mathrm{ROH})$ would preferentially react with the more reactive glycosyl donor (I) in an $\mathrm{S}_{\mathrm{N}} 2$ fashion, possibly via the tight ion-pair complex $\mathbf{K}$, providing the $\alpha$-glycoside $\mathbf{L}$. It is likely that the energy barrier for a nucleophilic substitution $\mathbf{I} \rightarrow \mathbf{L}$ (formation of the $\alpha$-glycoside) is marginally lower than that for the reaction $\mathbf{A} \rightarrow \mathbf{E}$ (formation of a $\beta$-glycoside). If the difference in the energy barrier were sufficient, it should be possible to direct the reaction toward the exclusive formation of $\alpha$-anomers.

Therefore, to obtain complete stereoselectivity, the entire glycosylation process has to be performed in a highly controlled manner. In this particular case, the control is achieved by the use of extremely mild catalyst $\left(\mathrm{R}_{4} \mathrm{NBr}\right)$, although very reactive substrates and prolonged reaction at times are required.

Other common approaches to control the stereoselectivity of glycosylation will be discussed in the subsequent sections. In addition to the apparent complexity of the glycosidation process, there are other competing processes that cannot be disregarded. These reactions often cause the compromised yields of the glycosylation products and further complicate the studies of the reaction mechanism. 
Elimination, substitution (formation of unexpected substitution products or hydrolysis at the anomeric center), cyclization (inter- and intramolecular orthoesterification), migration and redox are only a few to mention [71].

\section{5}

\section{Anomeric Effects}

A basic rule of conformational analysis known from the introductory organic chemistry is that an equatorial substituent of cyclic six-membered hydrocarbons is energetically favored. Hence, it is more stable owing to 1,3-diaxial interactions that would have occurred if a large substituent were placed in the axial position (Figure 1.3). For sugars, this rule is only applicable to hemiacetals (1-hydroxy derivatives) that are stabilized in $\beta$-orientation via intramolecular hydrogen-bond formation with O-5. Other polar substituents such as halide, OR or SR attached to the anomeric center of pyranoses/pyranosides prefer the axial orientation, which would be exclusive if the equilibrium at the anomeric center could be achieved. This phenomenon, which was first observed by Edward [72] and defined as anomeric effect by Lemieux [73], is partially responsible for the stereochemical outcome of processes taking place at the anomeric center of sugars $[64,74,75]$.

Cyclohexanes

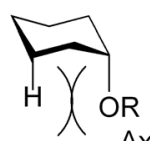
Axial<smiles>[R]O[C]1CCCC1</smiles>

Equatorial

\section{Hemiacetal}

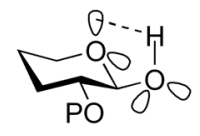

$\beta$-Anomer (destabilized)

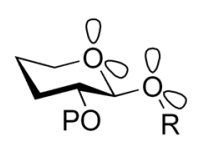

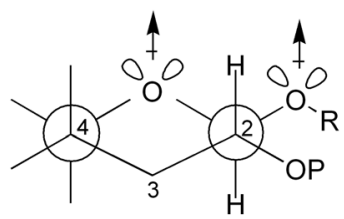<smiles>C1CCC2(C1)CCCC21CCO1</smiles>

$\alpha$-Anomer (stabilized)
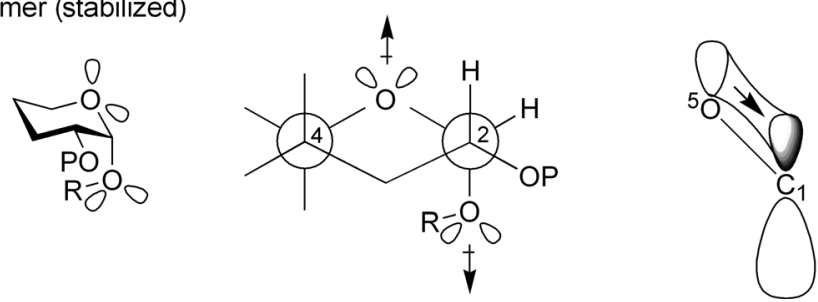

Figure 1.3 Anomeric effect. 
What are the origins of the anomeric effect, sometimes referred to as endoanomeric effect? In this context, the so-called exo-anomeric effect dealing with the stabilization of the $\beta$-anomer is of somewhat lesser influence on the overall process and will not be discussed herein [64]. One factor is that the substituent on the atom bonded to the ring at $\mathrm{C}-1$ has lone-pair electrons, which would have repulsive interactions with those of the ring oxygen $(\mathrm{O}-5)$ if the anomeric substituent is in the equatorial position ( $\beta$-position for D-sugars in ${ }^{4} \mathrm{C}_{1}$ conformation) but not if it is in the axial position (Figure 1.3). In addition, an electron-withdrawing axial substituent ( $\alpha$-anomer for D-sugars in ${ }^{4} \mathrm{C}_{1}$ conformation) is stabilized via hyperconjugation owing to the periplanar orientation of both nonbonding orbital of $\mathrm{O}-5$ and antibonding orbital of $\mathrm{C}-1$. This does not occur with the $\beta$-anomer, as the nonbonding orbital of $\mathrm{O}-5$ and antibonding orbital of $\mathrm{C}-1$ are in different planes and therefore are unable to interact.

\section{6}

\section{Stereoselectivity of Glycosylation}

As noted above, it is a general experience of carbohydrate synthesis that stereoselective preparation of 1,2-cis glycosides is more demanding than that of 1,2-trans glycosides. The formation of 1,2-trans glycosides is strongly favored by the neighboring-group participation (generation of intermediate acyloxonium ion). Typically, the use of a participating substituent at C-2 is sufficient to warrant stereoselective 1,2-trans glycosylation.

One of the factors affecting the stereochemical outcome of glycosidation of glycosyl donors bearing a nonparticipating substituent at C-2 is the anomeric effect, which favors $\alpha$-glycoside formation (1,2-cis for the D-gluco series). However, because of the irreversible character of glycosylation, the role of the anomeric effect is diminished and other factors affecting the orientation of the new glycosidic bond (discussed below) often come to the fore. Although variation of reaction conditions or structural elements of the reactants may lead to excellent 1,2-cis stereoselectivity, no successful comprehensive method for 1,2-cis glycosylation has emerged as yet.

\subsection{1}

\section{Structure of the Glycosyl Donor}

\subsubsection{Protecting Groups}

The most powerful impact on the stereoselectivity is produced from the neighboring group at C-2. Neighboring-group participation is one of the most powerful tools to direct stereoselectivity toward the formation of a 1,2-trans-linked product. The neighboring substituent at C- 2 is also responsible for the 'armed-disarmed' chemoselective glycosylation strategy [76]. The effects of the remote substituents are of lesser importance; however, there is strong evidence that a substituent at C-6 position may influence the stereochemical outcome of glycosylation dramatically. Although experimental proof has not emerged as yet, a possibility for the long-range 6-O-acyl or carbonate 
group assistance resulting in the preferential formation of $\alpha$-glucosides cannot be overruled [77-81]. It was also found that the steric bulkiness or strong electron-withdrawing properties of a substituent at C-6 are beneficial for 1,2-cis glucosylation, most likely because of shielding (sterically or electronically) the top face of the ring and, therefore, favoring the nucleophilic attack from the opposite side [14,82-88].

Although the effect of the C-6 substituent was found to be of minor importance for the derivatives of the D-galacto series [89], a remote effect is sufficiently strong when a participating moiety is present at C-4 [90,91]. Thus, the use of $p$-methoxybenzoyl (anisoyl) [91] and diethylthiocarbamoyl [81] groups was found to be exceptionally beneficial for the formation of $\alpha$-galactosides. Similar effects (including C-3 participation) were also detected for the derivatives of the L-fuco [92,93], L-rhamno [94], D-manno and D-gluco $[14,82,95]$ series [96]. It was noted that when the unprotected hydroxyl is present at C-4 of the sulfamidogalacto donor, the expected $\beta$-glycosyl formation occurs. However, when the hydroxyl group is blocked with benzyl or acyl, the process unexpectedly favors $\alpha$-glycoside formation. This phenomenon was rationalized via the formation of the intramolecular hydrogen bonding (C4-O- $\mathrm{H} \cdots \mathrm{O}-\mathrm{C} 5)$, destabilizing oxocarbenium ion contribution to the reaction mechanism that favors $\alpha$-glycosylation (pathway $b$, Scheme 1.1a). Torsional effects induced by the cyclic acetal protecting groups may also strongly affect the stereoselectivity at the anomeric center; however, these effects remain unpredictable at this stage [88,97-99].

\subsubsection{Leaving Group}

There are a large number of publications describing the comparison of various glycosylation methods applied for particular targets. However, only few principles could be reliably outlined. It has been unambiguously demonstrated that halides activated in the presence of a halide ion (from, e.g. $\mathrm{Bu}_{4} \mathrm{NBr}$ ) often provide the highest ratios of $\alpha$-/ $\beta$-glycosides [100-104]. Since in most cases the glycosylation reactions proceed via unimolecular $\mathrm{S}_{\mathrm{N}} 1$ mechanism, the orientation of the leaving group at the anomeric center is of lesser importance. However, the glycosylation reactions occasionally proceed via bimolecular $\mathrm{S}_{\mathrm{N}} 2$ mechanism with the inversion of the anomeric configuration. In this context, glycosyl donors with 1,2-cis orientation form 1,2-trans glycosides: for example glycosyl halides with insoluble catalysts (also used for $\beta$-mannosylation) [105], $\alpha$-imidates in the presence of boron trifluoride etherate $\left(\mathrm{BF}_{3}-\mathrm{Et}_{2} \mathrm{O}\right)$ at low temperature [106] and 1,2-anhydro sugars [107]. Conversely, 1,2-trans-oriented glycosyl donors stereospecifically afford 1,2-cis glycosides, for example highly reactive $\beta$-glucosyl halides [70], glycosyl thiocyanates $[39,108]$ and anomeric triflates formed in situ were found superior for the synthesis of $\beta$-mannosides $[109,110]$.

\subsection{2}

\section{Structure of the Glycosyl Acceptor}

\subsubsection{Position of the Hydroxyl}

Alcohol reactivity is typically inversely correlated with the 1,2-cis stereoselectivity the most reactive hydroxyls give the lowest $\alpha$ - $/ \beta$-ratios - the stronger the nucleophile, 
the faster the reaction, and hence the more difficult it is to control. Regarding the sugar or aliphatic glycosyl acceptors, the general rule normally states that glycosylation of more reactive primary hydroxyl provides poorer stereoselectivity in comparison to that when the secondary hydroxyls are involved [111]. The same principles are applicable for the synthesis of glycopeptides; thus, the glycosylation of the secondary hydroxyl of threonine typically gives higher $\alpha$-stereoselectivity than when primary hydroxyl group of serine is glycosylated with 2-azido-2-deoxy-galactosyl bromide or trichloroacetimidates $[112,113]$. Occasionally, primary hydroxyls provide somewhat higher 1,2-cis stereoselectivity in comparison to that of the secondary hydroxyl groups. This can serve as an indirect evidence of the glycosylation reaction proceeding via the bimolecular mechanism, at least partially.

\subsubsection{Protecting Groups}

It is well established that ester-electron-withdrawing substituents reduce electron density of the neighboring hydroxyl group by lowering its nucleophilicity $[88,105,114]$. This may improve stereoselectivity, as the reaction can be carried out in a more controlled manner. As an example, glycosylation of axial 4-OH of galactose often gives excellent 1,2-cis stereoselectivity, especially in combination with electronwithdrawing substituents (e.g. O-benzoyl, OBz) [115]. However, poorly reactive hydroxyls can lose their marginal reactivity completely when surrounded by the deactivating species, resulting in lower glycosylation yields.

\section{6 .3}

\section{Reaction Conditions}

\subsubsection{Solvent Effect}

Another important factor that influences the stereoselectivity at the anomeric center is the effect of the reaction solvent. In general, polar reaction solvents increase the rate of the $\beta$-glycoside formation via charge separation between $\mathrm{O}-5$ and $\beta$-O- 1 . If the synthesis of $\alpha$-glycosides is desired, $\mathrm{CH}_{2} \mathrm{Cl}_{2}, \mathrm{ClCH}_{2} \mathrm{CH}_{2} \mathrm{Cl}$ or toluene would be suitable candidates as reaction solvents. However, there are more powerful forces than simple solvation that have to be taken into consideration. The so-called participating solvents, such as acetonitrile and diethyl ether, were found to be the limiting cases for the preferential formation of $\beta$-D- and $\alpha$-D-glucosides, respectively [78]. These observations were rationalized as follows: if the reactions are performed in acetonitrile, the nitrilium cation formed in situ exclusively adopts axial orientation, allowing stereoselective formation of equatorially substituted glycosides (Scheme 1.3). This approach allows obtaining 1,2-trans glucosides with good stereoselectivity even with glycosyl donors bearing a nonparticipating substituent. On the contrary, ether-type reaction solvents such as diethyl ether, tetrahydrofuran [116] or dioxane [117] can also participate in the glycosylation process. Differently, in these cases the equatorial intermediate is preferentially formed, leading toward the axial glycosidic bond formation [85,86,118-120]. Nitroethane was also employed as a suitable solvent for 1,2-cis glycosylation [121]. 


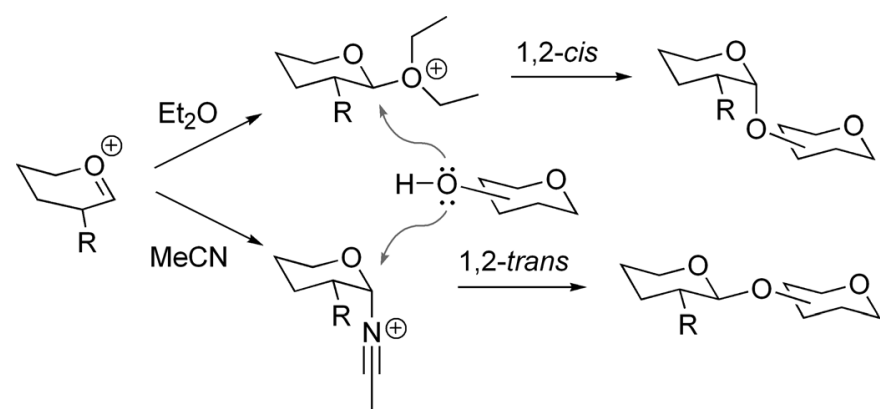

Scheme 1.3

\subsubsection{Promoter (Catalyst), Additions}

Milder activating conditions are generally beneficial for 1,2-cis glycosylation. Thus, halide-ion-catalyzed reactions give the best results for the glycosylation with glycosyl halides [70]; thioglycosides perform better when activated with a mild promoter, such as iodonium dicollidine perchlorate (IDCP) [122,123]; whereas trichloroacetimidates are best activated with the strong acidic catalysts, such as trimethylsilyl trifluoromethanesulfonate (TMS-triflate, TMSOTf) or triflouromethanesulfonic acid (triflic acid, TfOH) [106]. Various additions to the promoter systems often influence the stereochemical outcome of the glycosylation. Among the most remarkable examples is the use of perchlorate ion additive that was found to be very influential in 1,2-cis glycosylations $[118,124]$.

\subsubsection{Temperature and Pressure}

High pressure applied to the reactions with participating glycosyl donors further enhances 1,2-trans selectivity [125]; when the high-pressure conditions were applied for glycosylations with a nonparticipating glycosyl donor, remarkable increase in the reaction yield was noted with only marginal changes in stereoselectivity [126]. Kinetically controlled glycosylations at lower temperatures generally favor 1,2-trans glycoside formation $[100,120,127-130]$, although converse observations have also been reported $[131,132]$.

\subsection{4}

\section{Other Factors}

Unfavorable steric interactions that occur between glycosyl donor and acceptor in the transition state or other factors or conditions may unexpectedly govern the course and outcome of the glycosylation process. One of the most remarkable effects, the so-called 'double stereodifferentiation' takes place when stereochemical interactions between bulky substituents in glycosyl donor and glycosyl acceptor prevail the stereodirecting effect of a neighboring participating group. The pair of reagents where these interactions occur is called a 'mismatched pair'. Thus, only $\alpha$-linked product was unexpectedly formed with 2-phthalimido glycosyl acceptor (Scheme 1.4). [133]. A coupling of the same glycosyl donor with conformationally 

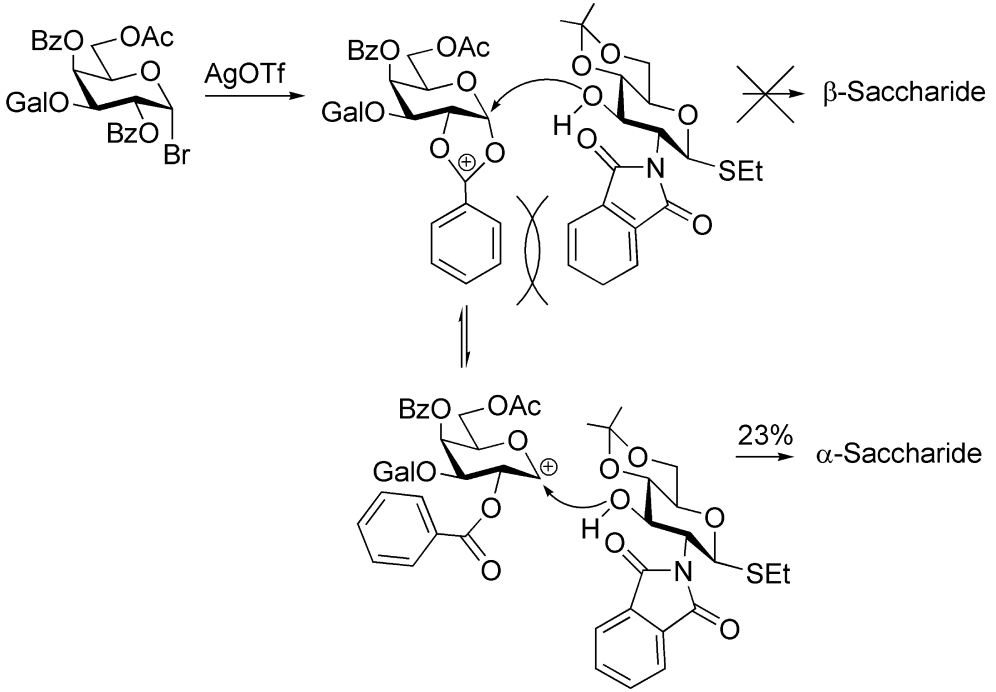

Scheme 1.4

modified 1,6-anhydro acceptor afforded $\beta$-linked oligosaccharide with $75 \%$ yield. It was also demonstrated that if this effect takes place with a sugar of the D-series, its Lenantiomer forms a matched pair with the same glycosyl acceptor.

\section{7}

\section{Special Cases of Glycosylation}

This section outlines special cases of glycosylation, not necessarily uncommon, which do not follow general conventions discussed above. It is not unusual when general glycosylation methods do not work or cannot be applied to the synthesis of glycosides described herein. The synthesis of each of these classes of compounds requires careful selection of techniques, their modification or design of conceptually new approaches. Sometimes special indirect or total synthesis based technologies have been developed and applied specifically to the synthesis of these targets.

\subsection{1}

\section{Aminosugars}

Glycosides of 2-amino-2-deoxy sugars are present in the most important classes of glycoconjugates and naturally occurring oligosaccharides, in which they are connected to other residues via either 1,2-cis or, more frequently, 1,2-trans glycosidic linkage [134-136]. In particular, 2-acetamido-2-deoxyglycosides, most common of the D-gluco and D-galacto series, are widely distributed in living organisms as glycoconjugates (glycolipids, lipopolysaccharides, glycoproteins) [134], glycosaminoglycans (heparin, 


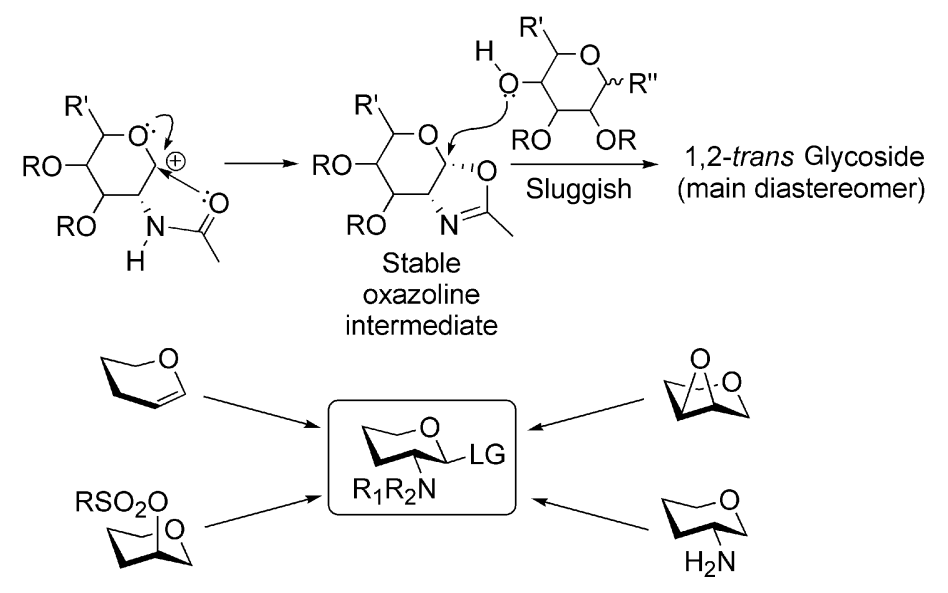

Scheme 1.5

heparin sulfate, dermatan sulfate, chondroitin sulfate, hyaluronic acid) [137] and so on $[138,139]$. Special efforts for the synthesis of glycosyl donors of 2-amino-2-deoxy sugars have been focusing on the development of simple, efficient, regio- and stereoselective procedures.

As a vast majority of naturally occurring 2-amino-2-deoxy sugars are $\mathrm{N}$-acetylated, from the synthetic point of view, a 2-acetamido-2-deoxy substituted glycosyl donor would be desirable to minimize protecting-group manipulations. For this type of glycosyl donors, however, the oxocarbenium ion rearranges rapidly into an oxazoline intermediate (Scheme 1.5). Even under harsh Lewis acid catalysis, this highly stable oxazoline intermediate does not exert strong glycosyl-donor properties. Although the synthesis of 1,2-trans glycosides is possible with the use of this type of glycosyl donors, the synthesis of 1,2-cis glycosides is a burden. As a matter of fact, the participating nature of the $\mathrm{N}$-acetyl moiety presents an obvious hindrance when the formation of the $\alpha$-linkage is desired. A minimal requirement for the synthesis of 1,2-cis glycosides would be the use of a C-2 nonparticipating moiety.

Nowadays, a variety of synthetic approaches to the synthesis of 2-amino-2-deoxyglycosides have been developed, and progress in this area has been reviewed [140-142]. These syntheses are started either from a glycosamine directly or by the introduction of nitrogen functionality to glycose or glycal derivatives. To this end, various glycosamine donors with modified functionalities have been investigated; in particular, those bearing an N-2 substituent capable of either efficient participation via acyloxonium, but not (2-methyl) oxazoline, intermediate for 1,2-trans glycosylation or a nonparticipating moiety for 1,2-cis glycosylation.

\subsection{2}

\section{Sialosides}

Sialic acids are nine-carbon monosaccharides involved in a wide range of biological phenomena. Their unique structure is characterized by the presence of a carboxylic 
group (ionized at physiological pH), deoxygenated C-3, glycerol chain at C-6 and differently functionalized C-5. Among the 50 derivatives reported so far, $\mathrm{N}$-acetylneuraminic acid (5-acetamido-3, 5-dideoxy-D-glycero-D-galacto-non-2-ulopyranosonic acid, Neu5Ac) is the most widespread. The natural equatorial glycosides and their unnatural axial counterparts are classified as $\alpha$ - and $\beta$-glycosides, respectively. In spite of extensive efforts and notable progress, the chemical synthesis of sialosides remains a significant challenge [143-146]. The presence of a destabilizing electronwithdrawing carboxylic group and the lack of a participating auxiliary often drive glycosylation reactions toward competitive elimination reactions, resulting in the formation of a 2,3-dehydro derivative and in poor stereoselectivity ( $\beta$-anomer). To overcome these problems, a variety of leaving groups and activation conditions for direct sialylations have been developed. It was also demonstrated that the $\mathrm{N}$-substituent at C-5 plays an influential role in both stereoselectivity of sialylation and the reactivity of sialyl donors [147].

Along with these studies, a variety of indirect methods for chemical sialylation have been developed. Several glycosyl donors derived from Neu5Ac have been prepared that possess an auxiliary at C-3. This auxiliary should control the anomeric selectivity of glycosylation by neighboring-group participation, leading to the formation of 2,3-trans-glycosides [143]. Thus, $\alpha$-glycosides are favored in the case of equatorial auxiliaries (Scheme 1.6), whereas $\beta$-glycosides are preferentially formed when the participating auxiliary is axial. The auxiliaries also help in preventing 2,3-elimination that often constitutes a major side reaction in the direct $O$-sialylations. One of the most important requirements is that an auxiliary should be easily installed prior to, and removed after, glycosylation. Usually, the auxiliaries are introduced by a chemical modification of the readily accessible 2,3dehydro derivative of Neu5Ac [148]. These transformations can be performed

Direct sialylations

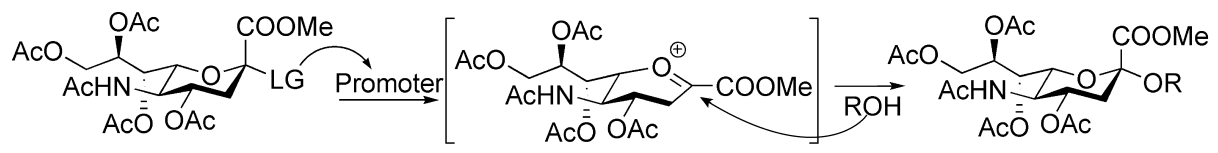

Indirect sialylations

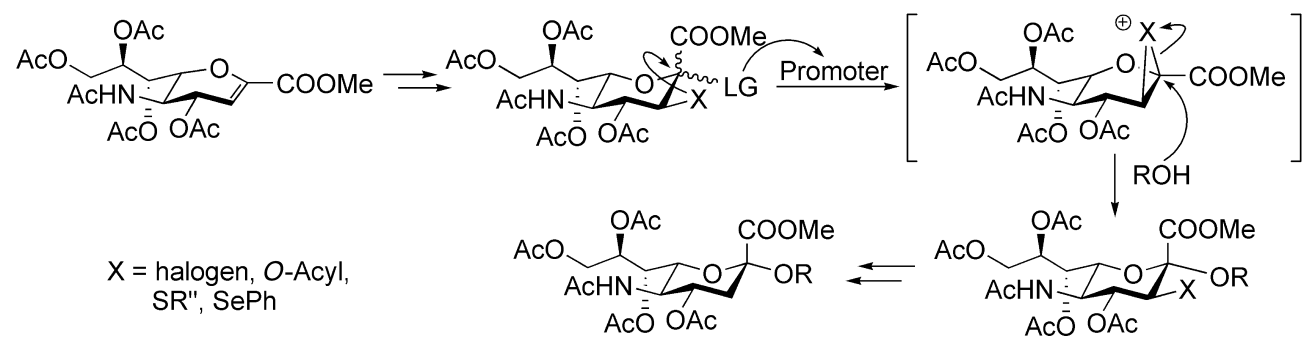

Scheme 1.6 
either through a 2,3-oxirane derivative or by a direct addition reaction to the double bond.

\subsection{3}

\section{Synthesis of 2-Deoxyglycosides}

2-Deoxyglycosides are important constituents of many classes of antibiotics. The development of reliable methods for stereoselective synthesis of both $\alpha$ - and $\beta$-2deoxyglycosides has become an important area of research and development of new classes of drugs and glycomimetics $[149,150]$. It should be noted that because of the lack of anchimeric assistance of the substituent at C-2, the synthesis of both types of linkages represents a notable challenge. On one hand, the direct glycosylation of 2-deoxy glycosyl donors often results in the formation of anomeric mixtures. Similar to that of conventional glycosylation, the solvent and promoter effects play important stereodirecting roles in the synthesis. On the other hand, similar to that discussed for the sialosides, a participating auxiliary can be used to add to the stereoselectivity of glycosylation. Usually this moiety is introduced through 1,2dehydro derivatives with concomitant or sequential introduction of the anomeric leaving group. The methods employing both axial and equatorial substituents are known to result in the formation of 1,2-trans glycosides, which upon 2-deoxygenation can be converted into the respective targets. Although this latter approach requires additional synthetic steps, it is often preferred because it provides higher level of stereocontrol.

\subsection{4}

\section{Synthesis of $\beta$-Mannosides}

$\beta$-Mannosyl residues are frequently found in glycoproteins. The chemical synthesis of 1,2-cis- $\beta$-mannosides cannot be achieved by relying on the anomeric effect that would favor axial $\alpha$-mannosides at the equilibrium. In addition, it is further disfavored by the repulsive interactions that would have occurred between the axial C-2 substituent and the nucleophile approaching from the top face of the ring. For many years the only direct procedure applicable to $\beta$-mannosylation Ag-silicate promoted glycosidation of $\alpha$-halides - was assumed to follow bimolecular $\mathrm{S}_{\mathrm{N}} 2$ mechanism $[13,14]$. The difficulty of the direct $\beta$-mannosylation was addressed by developing a variety of indirect approaches such as C-2 oxidationreduction, C-2 inversion, anomeric alkylation and intramolecular aglycone delivery (Scheme 1.7) [151-155]. This was the standing in this field before Crich and coworkers discovered that 4,6-O-benzylidene protected sulfoxide [109] or thiomannoside [110] glycosyl donors provide excellent $\beta$-manno stereoselectivity. Mechanistic and spectroscopic studies showed that anomeric $\alpha$-O-triflates generated in situ as reactive intermediates can be stereospecifically substituted. On a similar note, 2-(hydroxycarbonyl)benzyl glycosides have proven to be versatile glycosyl donors for the synthesis of $\beta$-mannosides via anomeric triflate intermediates [58]. 


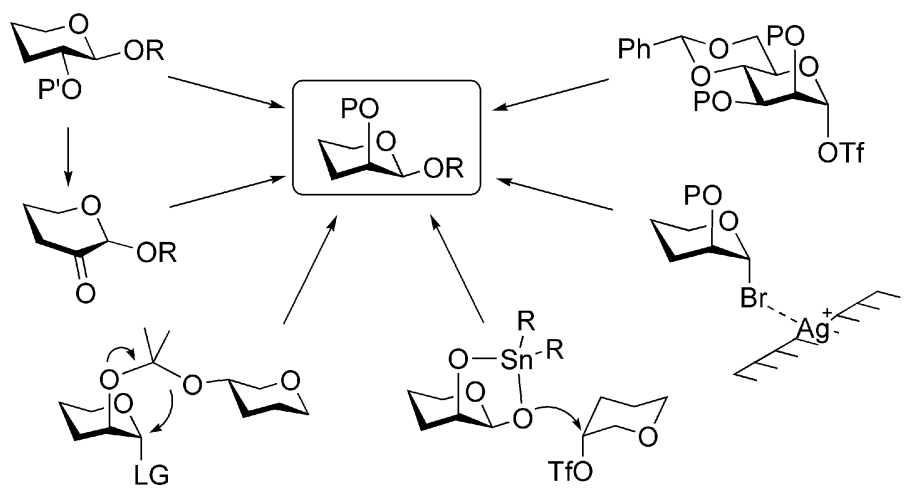

Scheme 1.7

\subsection{5}

\section{Synthesis of Furanosides}

In comparison to their six-membered ring counterparts, furanosides are relatively rare. Nevertheless, their presence in a variety of glycostructures from bacteria, parasites and fungi makes this type of glycosidic linkage an important synthetic target [156,157]. The synthesis of 1,2-trans furanosides is relatively straightforward and, similar to that of pyranosides, can be reliably achieved with the use of glycosyl donors bearing a participating group at C-2. In contrast, the construction of 1,2-cisglycofuranosidic linkage is difficult, even more so than with pyranosides, because the stereocontrol in glycofuranosylation cannot be added by the anomeric effect owing to the conformational flexibility of the five-membered ring. In fact, both stereoelectronic and steric effects favor the formation of 1,2-trans glycofuranosides. Despite some recent progress, stereoselective synthesis of 1,2-cis glycofuranosides has been one of the major challenges of synthetic chemistry. General glycosylation methods, involving glycosyl fluorides [158], trichloroacetimidates [159], and thioglycosides [156,160] along with less common and indirect techniques [161-164], were applied to 1,2-cis furanosylation. More recently, a notable improvement in stereoselectivity of 1,2-cis furanosylation was achieved by using glycosyl donors in which the ring has been locked into a single conformation. These examples include 2,3-anhydro [165-169], 3,5-O-(di-tert-butylsilylene) [170,171] and 3,5-O-tetraisopropyldisiloxanylidene [172] protected bicyclic glycosyl donors.

\section{8}

\section{Glycosylation and Oligosaccharide Sequencing}

Stereoselective glycosylation is only a part of the challenge that synthetic chemists confront during the synthesis of oligosaccharides. Regardless of the efficiency of a single glycosylation, a traditional stepwise approach requires subsequent conversion of the disaccharide derivative into the second-generation glycosyl acceptor or glycosyl 


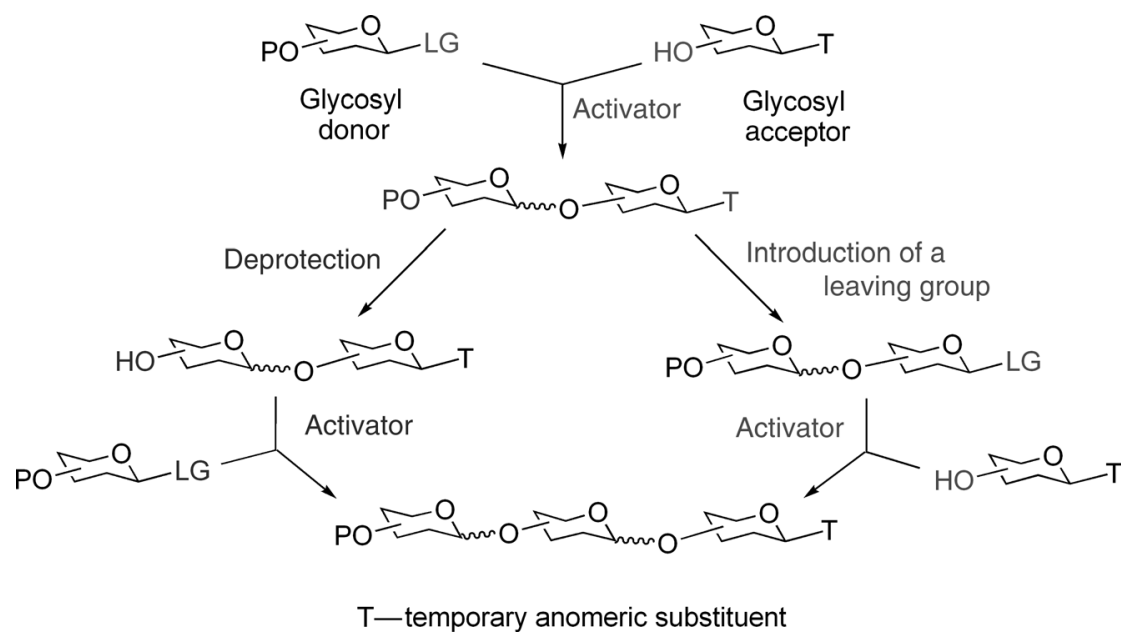

Scheme 1.8 Linear oligosaccharide synthesis.

donor (see Scheme 1.8). The modified disaccharides are then coupled with a glycosyl donor (or acceptor) to obtain a trisaccharide. This reaction sequence is then repeated again until oligosaccharide of the desired chain length is obtained.

It has become apparent that the linear approach is too inefficient and lengthy, especially when applied to the synthesis of large oligosaccharides. As a result, the past two decades have witnessed a dramatic improvement in the methods and strategies used for oligosaccharide synthesis. The first attempt to address challenges associated with the linear stepwise approach was the development of a convergent approach $[105,173,174]$. According to this approach, oligosaccharide building blocks are obtained separately and then coupled together, which, in comparison to the linear approach, allows formation of larger saccharides faster. It is especially advantageous if the synthesis of two or more sequential repeat units is desired for the introduction of a 'difficult' linkage, such as 1,2-cis, at an earlier stage of the saccharide assembly to avoid complicated diastereomer separation at the later stage.

When the arsenal of the glycosylation techniques was limited to Fischer and Koenigs-Knorr approaches (or their variations), the oligosaccharide assembly was limited to the linear and block techniques. However, when stable glycosyl donors such as thioglycosides or O-alkenyl glycosides emerged, a question of selective or chemoselective activation arose. In brief, most recently developed strategies fit into three broad categories: leaving-group-based (selective or orthogonal activation), preactivationbased and protecting-group-based (armed-disarmed) strategies [175].

\subsection{1}

\section{Leaving-Group-Based Strategies}

The schematic outline of the stepwise selective activation is shown in Scheme 1.9; thus, a glycosyl donor, bearing a reactive $\mathrm{LG}^{\mathrm{a}}$, is coupled with a glycosyl acceptor, 


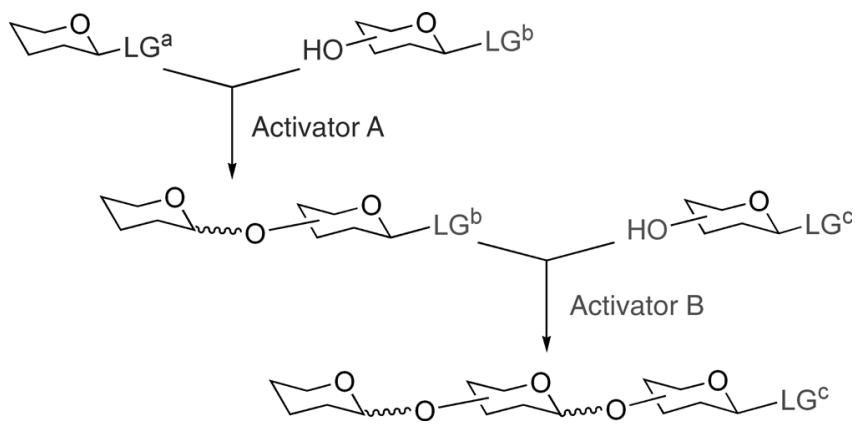

Scheme 1.9 Stepwise selective activation.

bearing a relatively stable $\mathrm{LG}^{\mathrm{b}}$ at the anomeric center. The major requirement for this reaction to take place is the use of a suitable activator that would selectively activate $\mathrm{LG}^{\mathrm{a}}$ but not $\mathrm{LG}^{\mathrm{b}}$ (Activator A). Early studies involved the activation of alkyl halides over S-alkyl/aryl glycosides [173,176-179]. Subsequently, other examples of suitable LG ${ }^{\mathrm{a}}$ for selective activations have become available: trichloroacetimidates, phosphite, phosphate, thioimidate, hemiacetal, sulfoxide, selenoglycoside, orthoester and so on [175]. Many of these couplings were performed with the use of either S-alkyl/aryl or Oalkenyl/hetaryl moieties as $\mathrm{LG}^{\mathrm{b}}$. In principle, the activation sequence can be continued providing that there is an $\mathrm{LG}^{\mathrm{c}}$ that would withstand reaction conditions for the $\mathrm{LG}^{\mathrm{b}}$ activation (Activator B). However, these elongated multistep sequences are not yet routinely available. Few available examples include the following three-step activation sequences: bromide as $\mathrm{LG}^{\mathrm{a}}$, Se-phenyl as $\mathrm{LG}^{\mathrm{b}}$, and $S$-ethyl as $\mathrm{LG}^{\mathrm{c}}$ [180]; S-benzoxazolyl (SBox) as LGa , S-ethyl as LG' , and O-pentenyl as $\mathrm{LG}^{\mathrm{c}}$ [181]; SBox as LG ${ }^{\mathrm{a}}$, S-thiazolinyl (STaz) as LG ${ }^{\mathrm{b}}$, S-ethyl as $\mathrm{LG}^{\mathrm{C}}$ [182] and so on [183].

The combination of two chemically distinct glycosylation reactions, in which one of the leaving groups is activated while the other one remains intact and vice versa, has led to the discovery of the orthogonal glycosylation strategy [184]. This unique and virtually one of the most advanced techniques for oligosaccharide synthesis requires the use of orthogonal glycosyl donors [185]. Typically, phenyl thioglycosides are selectively activated over glycosyl fluorides and vice versa [184,186,187]. Recently, it has been discovered that a combination of $S$-ethyl and $S$-thiazolinyl glycosides also allows orthogonal activation [188].

A one-pot technique, combining two or more glycosylation steps based on activation of one donor over another, have also been developed [182,189-191]. This one-pot technique is virtually a variation of a simple stepwise selective activation strategy, which allows further improvement in the efficiency of the synthesis by avoiding the necessity for isolation (and purification) of the intermediates.

\subsection{2}

\section{Two-Step Activation and Preactivation Strategies}

According to the two-stage activation (or preactivation) approach, both glycosyl donor and glycosyl acceptor initially bear the same type of a leaving group ( $\left.\mathrm{LG}^{\mathrm{a}}\right)$. 


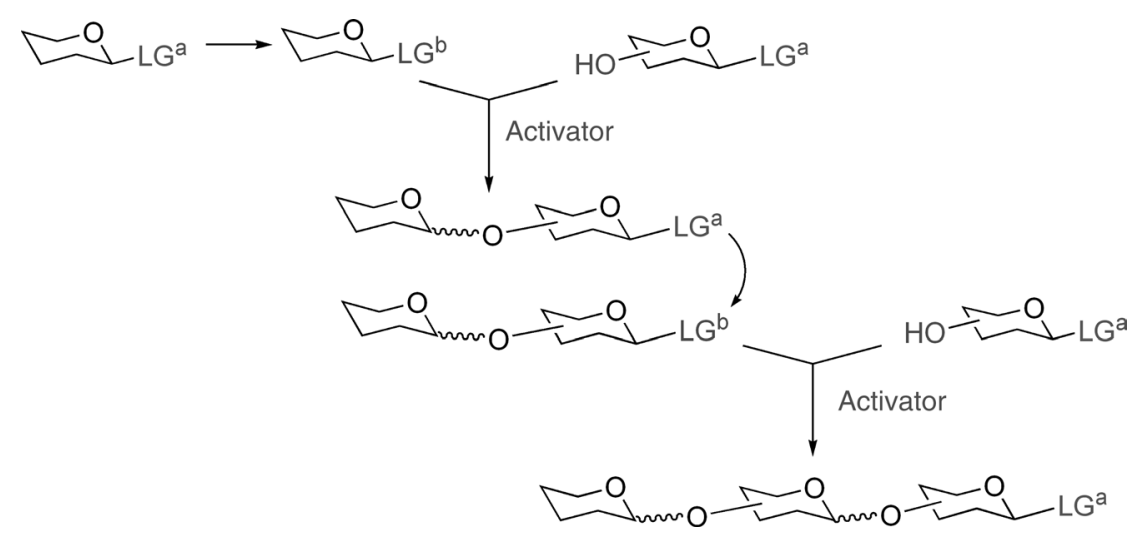

Scheme 1.10 Two-step activation concept.

However, to couple these two reactants, the $\mathrm{LG}^{\mathrm{a}}$ of the potential glycosyl donor unit is first converted into an $\mathrm{LG}^{\mathrm{b}}$, which is then selectively activated over $\mathrm{LG}^{\mathrm{a}}$ of the glycosyl acceptor in the presence of a selective activator (Activator B, Scheme 1.10). This twostep activation sequence can be reiterated; for this purpose the leaving group of the obtained disaccharide $\mathrm{LG}^{\mathrm{a}}$ is again converted into $\mathrm{LG}^{\mathrm{b}}$ and so on. This concept was discovered for S-ethyl ( $\mathrm{LG}^{\mathrm{a}}$ ) and bromo ( $\mathrm{LG}^{\mathrm{b}}$ ) moieties [173] and further explored for other systems [176,192-194]. The same principle was applied by Danishefsky in the reiterative glycal assembly approach $[43,195,196]$. This technique involves the transformation of glycals into 1,2-anhydro sugars, which can be easily glycosidated with partially protected glycal-based glycosyl acceptors. Recently, the versatility of the twostep activation was demonstrated by a one-pot preactivation procedure $[197,198]$, according to which $S$-tolyl glycosides are converted in situ into a reactive intermediate.

Similar principle is executed in the active-latent approach that has been applied to a number of systems $[51,193,199,200]$. It is important to note that the conversion between $\mathrm{LG}^{\mathrm{a}}$ and $\mathrm{LG}^{\mathrm{b}}$ in the active-latent approach does not involve substitution at the anomeric center; instead, a simple modification of the leaving group itself is executed. Recently, the application of this technique was enhanced by the discovery that 2-(benzyloxycarbonyl)benzyl glycosides are perfectly stable compounds, whereas the corresponding 2-(hydroxycarbonyl)benzyl moiety, obtained by the selective hydrogenolysis is an excellent leaving group that can be readily activated [58]. This and other conceptually similar recent discoveries $[56,201]$ open new exciting perspectives for further development of the activelatent strategy.

\section{8 .3}

\section{Protecting-Group-Based Strategies}

Another efficient strategy, the armed-disarmed approach, developed by FraserReid is based on the chemoselectivity principle [193,202]. According to this 
20| 1 General Aspects of the Glycosidic Bond Formation
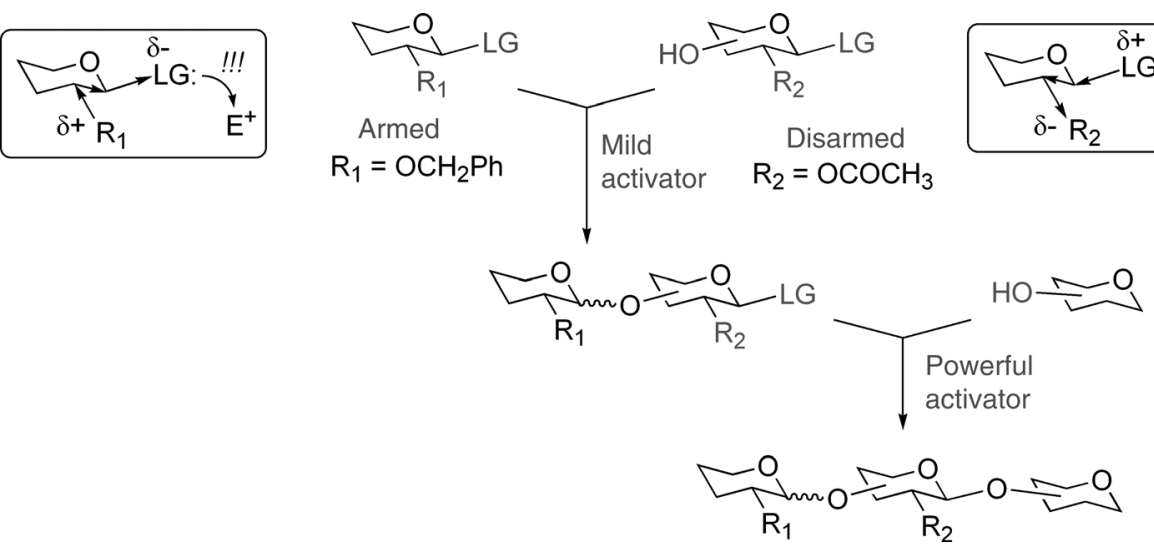

Scheme 1.11 Armed-disarmed strategy.

technique, a benzylated (electronically activated, armed) glycosyl donor is chemoselectively activated over the acylated (electronically deactivated, disarmed) derivative bearing the same type of LG in the presence of a mild promoter (Scheme 1.11). At the first step a 1,2-cis-linked disaccharide is preferentially obtained because of the use of the ether-type arming substituent, a nonparticipating group (O-benzyl). The obtained disaccharide can then be used for 1,2-trans glycosylation directly in the presence of a more potent promoter, capable of activating the disarmed LG.

Initially developed for O-pentenyl glycosides, this concept was further explored for the chemoselective glycosidations of ethyl thioglycosides, selenoglycosides, fluorides, phosphoroamidates, substituted thioformimidates, glycals, benzoxazolyl and thiazolinyl glycosides [175]. The chemoselective activation has become the basis of programmable multistep reactivity-based technique, including highly efficient one-pot approaches [203,204]. Further insights into the armed-disarmed approach came with the observation of the unusual reactivity pattern of the SBox glycosides. Thus, it was demonstrated that glycosyl donors with 2-O-benzyl-3,4,6-tri-O-acyl protecting-group pattern are even more deactivated than the corresponding 'disarmed' peracyl derivatives [205]. Although the exact nature of this so-called $\mathrm{O}-2 / \mathrm{O}-5$ cooperative interesting effect is not yet understood, it has been postulated that the intermediate carbocation stabilization via the acyloxonium ion of the peracylated donor is favored over the oxocarbenium ion stabilization of the 2-O-benzyl-3,4,6-tri-O-acylated donors. Another interesting concept is the use of 2-O-picolyl substituent as an arming participating group. According to this so-called inverse armed-disarmed method, the 1,2trans glycosidic linkage can be chemoselectively introduced at the first glycosylation step [206]. 


\section{Conclusions and Outlook}

The progress in the area of chemical glycosylation has significantly improved our ability to synthesize various glycosidic linkages with impressive yields and stereoselectivity. But, can we conclude that we have entirely solved the problem of chemical glycosylation? Unfortunately not, and hopefully this chapter introduced the reader to the challenge of chemical glycosylation, a variety of factors, conditions, and driving forces influencing all aspects of this complex chemical reaction as well as prepared for studying more specialized material dedicated to particular methods and strategies employed in modern carbohydrate chemistry. Recent progress made in the area of development of new coupling methods and highly efficient strategies for expeditious oligosaccharide synthesis will ultimately provide an efficient and trouble-free access to complex saccharides. This goal cannot be achieved without the comprehensive knowledge of the glycosylation mechanism and driving forces of glycosylation and competing side processes. It is likely that the consecutive scientific development in this field will be focusing on studying the fundamental mechanistic aspects of glycosylation rather than developing additional anomeric leaving groups.

\section{References}

1 Michael, A. (1879) American Chemical Journal, 1, 305-312.

2 Fischer, E. (1893) Chemische Berichte, 26, 2400-2412.

3 Koenigs, W. and Knorr, E. (1901) Chemische Berichte, 34, 957-981.

4 Igarashi, K. (1977) Advances in Carbohydrate Chemistry and Biochemistry, 34, 243-283.

5 Zemplen, G. and Gerecs, A. (1930) Chemische Berichte, 63B, 2720-2729.

6 Helferich, B. and Wedemeyer, K.F. (1949) Liebigs Annalien der Chemie, 563, 139-145.

7 Helferich, B. and Zirner, J. (1962) Chemische Berichte, 95, 2604-2611.

8 Conrow, R.B. and Bernstein, S. (1971) Journal of Organic Chemistry, 36, 863-870.

9 Helferich, B. and Schmitz-Hillebrecht, E. (1933) Chemische Berichte, 66B, 378-383.

10 Lemieux, R.U. (1954) Advances in Carbohydrate Chemistry and Biochemistry, 9, 1-57, and references therein.

11 Ness, R.K., Fletcher, H.G. and Hudson, C.S. (1951) Journal of the American Chemical Society, 73, 959-963.
12 Ness, R.K. and Fletcher, H.G. (1956) Journal of the American Chemical Society, 78, 4710-4714.

13 Paulsen, H. and Lockhoff, O. (1981) Chemische Berichte, 114, 3102-3114.

14 van Boeckel, C.A.A., Beetz, T. and van Aelst, S.F. (1984) Tetrahedron, 40, 40974107, and references therein.

15 Toshima, K. and Tatsuta, K. (1993) Chemical Reviews, 93, 1503-1531.

16 Davis, B.G. (2000) Journal of the Chemical Society, Perkin Transactions, 1, 2137-2160.

17 Ferrier, R.J., Hay, R.W. and Vethaviyasar, N. (1973) Carbohydrate Research, 27, 55-61.

18 Nicolaou, K.C., Seitz, S.P. and Papahatjis, D.P. (1983) Journal of the American Chemical Society, 105, 2430-2434.

19 Garegg, P.J., Henrichson, C. and Norberg, T. (1983) Carbohydrate Research, 116, 162-165.

20 Oscarson, S. (2001) Glycoscience: Chemistry and Chemical Biology, vol. 1 (eds B. Fraser-Reid, K. Tatsuta and J. Thiem), Springer, Berlin, Heidelberg, New York, pp. 643-671. 
21 Bochkov, A.F. and Kochetkov, N.K. (1975) Carbohydrate Research, 39, 355-357.

22 Kochetkov, N.K., Backinowsky, L.V. and Tsvetkov, Y.E. (1977) Tetrahedron Letters, 41, 3681-3684.

23 Pougny, J.R., Jacquinet, J.C., Nassr, M., Duchet, D., Milat, M.L. and Sinay, P. (1977) Journal of the American Chemical Society, 99, 6762-6763.

24 Schmidt, R.R. and Michel, J. (1980) Angewandte Chemie (International Edition in English), 19, 731-732.

25 Mukaiyama, T., Nakatsuka, T. and Shoda, S.I. (1979) Chemistry Letters, 487-490.

26 Hanessian, S., Bacquet, C. and Lehong, N. (1980) Carbohydrate Research, 80, c17-c22.

27 Woodward, R.B., Logusch, E., Nambiar, K.P., Sakan, K., Ward, D.E., Au-Yeung, B.W., Balaram, P., Browne, L.J., Card, P.J. and Chen, C.H. (1981) Journal of the American Chemical Society, 103, 32153217.

28 Mukaiyama, T., Murai, Y. and Shoda, S. (1981) Chemistry Letters, 431-432.

29 Schmidt, R.R., Castro-Palomino, J.C. and Retz, O. (1999) Pure and Applied Chemistry, 71, 729-744.

30 Schmidt, R.R. and Jung, K.H. (2000) Carbohydrates in Chemistry and Biology, vol. 1 (eds B. Ernst, G.W. Hart and P. Sinay), Wiley-VCH Verlag $\mathrm{GmbH}$, Weinheim, New York, pp. 5-59.

31 Garegg, P.J. (1997) Advances in Carbohydrate Chemistry and Biochemistry, 52, 179-205.

32 Oscarson, S. (2000) Carbohydrates in Chemistry and Biology, vol. 1 (eds B. Ernst, G.W. Hart and P. Sinay), Wiley-VCH Verlag GmbH, Weinheim, New York, pp. 93-116.

33 Codee, J.D.C., Litjens, R.E.J.N., van den Bos, L.J., Overkleeft, H.S. and van der Marel, G.A. (2005) Chemical Society Reviews, 34, 769-782.

34 Nicolaou, K.C. and Ueno, H. (1997) Preparative Carbohydrate Chemistry (ed. S. Hanessian), Marcel Dekker, Inc., New York, pp. 313-338.
35 Mukaiyama, T. (2004) Angewandte Chemie (International Edition), 43, 5590-5614.

36 Boursier, M. and Descotes, G. (1989) Comptes Rendus de l'Academie des Sciences Serie II, 308, 919-921.

37 Koide, K., Ohno, M. and Kobayashi, S. (1991) Tetrahedron Letters, 32, 7065-7068.

38 Kunz, H. and Zimmer, J. (1993) Tetrahedron Letters, 34, 2907-2910.

39 Kochetkov, N.K., Klimov, E.M. and Malysheva, N.N. (1989) Tetrahedron Letters, 30, 5459-5462.

40 Briner, K. and Vasella, A. (1989) Helvetica Chimica Acta, 72, 1371-1382.

41 Marra, A. and Sinay, P. (1990) Carbohydrate Research, 195, 303-308.

42 Friesen, R.W. and Danishefsky, S.J. (1989) Journal of the American Chemical Society, 111, 6656-6660.

43 Halcomb, R.L. and Danishefsky, S.J. (1989) Journal of the American Chemical Society, 111, 6661-6666.

44 Kondo, H., Ichikawa, Y. and Wong, C.H. (1992) Journal of the American Chemical Society, 114, 8748-8750.

45 Martin, T.J. and Schmidt, R.R. (1992) Tetrahedron Letters, 33, 6123-6126.

46 Kahne, D., Walker, S., Cheng, Y. and van Engen, D. (1989) Journal of the American Chemical Society, 111, 6881-6882.

47 Brown, D.S., Ley, S.V. and Vile, S. (1988) Tetrahedron Letters, 29, 4873-4876.

48 Mehta, S. and Pinto, B.M. (1991) Tetrahedron Letters, 32, 4435-4438.

49 Fraser-Reid, B., Konradsson, P., Mootoo, D.R. and Udodong, U. (1988) Journal of the Chemical Society: Chemical Communications, 823-825.

50 Marra, A., Esnault, J., Veyrieres, A. and Sinay, P. (1992) Journal of the American Chemical Society, 114, 6354-6360.

51 Boons, G.J. and Isles, S. (1994) Tetrahedron Letters, 35, 3593-3596.

52 Huchel, U., Schmidt, C. and Schmidt, R.R. (1998) European Journal of Organic Chemistry, 1353-1360, and references therein.

53 Gervay, J. and Hadd, M.J. (1997) Journal of Organic Chemistry, 62, 6961-6967. 
54 Plante, O.J., Andrade, R.B. and Seeberger, P.H. (1999) Organic Letters, 1, 211-214.

55 Stick, R.V., Tilbrook, D.M.G. and Williams, S.J. (1997) Australian Journal of Chemistry, 50, 237-240.

56 Hinklin, R.J. and Kiessling, L.L. (2001) Journal of the American Chemical Society, 123, 3379-3380.

57 Davis, B.G., Ward, S.J. and Rendle, P.M. (2001) Chemical Communications, 189190.

58 Kim, K.S., Kim, J.H., Lee, Y.J., Lee, Y.J. and Park, J. (2001) Journal of the American Chemical Society, 123, 8477-8481.

59 Demchenko, A.V., Malysheva, N.N. and De Meo, C. (2003) Organic Letters, 5, 455458.

60 Demchenko, A.V., Pornsuriyasak, P., De Meo, C. and Malysheva, N.N. (2004) Angewandte Chemie (International Edition), 43, 3069-3072.

61 Adinolfi, M., Barone, G., Iadonisi, A. and Schiattarella, M. (2002) Synlett, 269-270

62 Adinolfi, M., Barone, G., Iadonisi, A. and Schiattarella, M. (2002) Tetrahedron Letters, 43, 5573-5577.

63 Gin, D. (2002) Journal of Carbohydrate Chemistry, 21, 645-665.

64 Tvaroska, I. and Bleha, T. (1989) Advances in Carbohydrate Chemistry and Biochemistry, 47, 45-123.

65 Demchenko, A.V. (2003) Synlett, 12251240.

66 Demchenko, A.V. (2003) Current Organic Chemistry, 7, 35-79.

67 Goodman, L. (1967) Advances in Carbohydrate Chemistry and Biochemistry, 22, 109-175.

68 Fife, T.H., Bembi, R. and Natarajan, R. (1996) Journal of the American Chemical Society, 118, 12956-12963.

69 Nukada, T., Berces, A., Zgierski, M.Z. and Whitfield, D.M. (1998) Journal of the American Chemical Society, 120, 1329113295.

70 Lemieux, R.U., Hendriks, K.B., Stick, R. V. and James, K. (1975) Journal of the
American Chemical Society, 97, 4056-

4062, and references therein.

71 Bochkov, A.F. and Zaikov, G.E. (1979) Chemistry of the O-Glycosidic Bond: Formation and Cleavage, Pergamon Press.

72 Edward, J.T. (1955) Chemistry \& Industry, 1102-1104.

73 Lemieux, R.U. (1971) Pure and Applied Chemistry, 25, 527-548, and references therein.

74 Wolfe, S., Whangbo, M.H. and Mitchell, D.J. (1979) Carbohydrate Research, 69, 1-26.

75 Box, V.G.S. (1990) Heterocycles, 31, 11571181.

76 Fraser-Reid, B., Wu, Z., Udodong, U.E. and Ottosson, H. (1990) Journal of Organic Chemistry, 55, 6068-6070.

77 Ishikawa, T. and Fletcher, H.G. (1969) Journal of Organic Chemistry, 34, 563-571.

78 Eby, R. and Schuerch, C. (1974) Carbohydrate Research, 34, 79-90, and references therein.

79 Koto, S., Yago, K., Zen, S., Tomonaga, F. and Shimada, S. (1986) Bulletin of the Chemical Society of Japan, 59, 411-414.

80 Dasgupta, F. and Garegg, P.J. (1990) Carbohydrate Research, 202, 225-238.

81 Mukaiyama, T., Suenaga, M., Chiba, H. and Jona, H. (2002) Chemistry Letters, 56-57.

82 van Boeckel, C.A.A. and Beetz, T. (1985) Recueil Des Travaux Chimiques Des PaysBas, 104, 171-173.

83 Fei, C.P. and Chan, T.H. (1987) Tetrahedron Letters, 28, 849-852.

84 Houdier, S. and Vottero, P.J.A. (1992) Carbohydrate Research, 232, 349-352.

85 Fukase, K., Kinoshita, I., Kanoh, T., Nakai, Y., Hasuoka, A. and Kusumoto, S. (1996) Tetrahedron, 52, 3897-3904.

86 Fukase, K., Nakai, Y., Kanoh, T. and Kusumoto, S. (1998) Synlett, 84-86.

87 Fukase, K., Nakai, Y., Egusa, K., Porco, J. A. and Kusumoto, S. (1999) Synlett, 1074 1078.

88 Green, L.G. and Ley, S.V. (2000) Carbohydrates in Chemistry and Biology, vol. 1 (eds B. Ernst, G.W. Hart and 
P. Sinay), Wiley-VCH Verlag $\mathrm{GmbH}$, Weinheim, New York, pp. 427-448.

89 Lucas, T.J. and Schuerch, C. (1975) Carbohydrate Research, 39, 39-45.

90 Nakahara, Y. and Ogawa, T. (1987) Tetrahedron Letters, 28, 2731-2734.

91 Demchenko, A.V., Rousson, E. and Boons, G.J. (1999) Tetrahedron Letters, 40, 6523-6526.

92 Zuurmond, H.M., van der Laan, S.C., van der Marel, G.A. and van Boom, J.H. (1991) Carbohydrate Research, 215, c1-c3.

93 Gerbst, A.G., Ustuzhanina, N.E., Grachev, A.A., Tsvetkov, D.E., Khatuntseva, E.A. and Nifant'ev, N.E. (I999) Mendeleev Communications, 114116.

94 Yamanoi, T., Nakamura, K., Takeyama, H., Yanagihara, K. and Inazu, T. (1994) Bulletin of the Chemical Society of Japan, 67, 1359-1366.

95 Ustyuzhanina, N., Komarova, B., Zlotina, N., Krylov, V., Gerbst, A.G., Tsvetkov, Y. and Nifantiev, N.E. (2006) Synlett, 6, 921923.

96 Kwon, O. and Danishefsky, S.J. (1998) Journal of the American Chemical Society, 120, 1588-1599.

97 Crich, D. and Sun, S. (1998) Journal of the American Chemical Society, 120, 435-436.

98 Anilkumar, G., Nair, L.G., Olsson, L., Daniels, J.K. and Fraser-Reid, B. (2000) Tetrahedron Letters, 41, 7605-7608.

99 Crich, D., Cai, W. and Dai, Z. (2000) Journal of Organic Chemistry, 65, 12911297.

100 Andersson, F., Fugedi, P., Garegg, P.J. and Nashed, M. (1986) Tetrahedron Letters, 27, 3919-3922.

101 Kihlberg, J.O., Leigh, D.A. and Bundle, D. R. (1990) Journal of Organic Chemistry, 55, 2860-2863.

102 Garegg, P.J., Oscarson, S. and Szonyi, M. (1990) Carbohydrate Research, 205, 125132.

103 Vermeer, H.J., van Dijk, C.M., Kamerling, J.P. and Vliegenthart, J.F.G. (2001) European Journal of Organic Chemistry, 193-203.
104 Hadd, M.J. and Gervay, J. (1999) Carbohydrate Research, 320, 61-69.

105 Paulsen, H. (1982) Angewandte Chemie (International Edition in English), 21, 155173.

106 Schmidt, R.R. and Jung, K.H. (1997) Preparative Carbohydrate Chemistry (ed. S. Hanessian), Marcel Dekker, Inc., New York, pp. 283-312.

107 Williams, L.J., Garbaccio, R.M. and Danishefsky, S.J. (2000) Carbohydrates in Chemistry and Biology, vol. 1 (eds B. Ernst, G.W. Hart and P. Sinay), Wiley-VCH Verlag GmbH, Weinheim, New York, pp. 61-92.

108 Kochetkov, N.K., Klimov, E.M., Malysheva, N.N. and Demchenko, A.V. (1991) Carbohydrate Research, 212, 77-91.

109 Crich, D. and Sun, S. (1996) Journal of Organic Chemistry, 61, 4506-4507.

110 Crich, D. and Smith, M. (2000) Organic Letters, 2, 4067-4069.

111 Chen, Q. and Kong, F. (1995) Carbohydrate Research, 272, 149-157.

112 Sames, D., Chen, X.T. and Danishefsky, S.J. (1997) Nature, 389, 587-591.

113 Schwartz, J.B., Kuduk, S.D., Chen, X.T., Sames, D., Glunz, P.W. and Danishefsky, S.J. (1999) Journal of the American Chemical Society, 121, 2662-2673.

114 Sinay, P. (1978) Pure and Applied Chemistry, 50, 1437-1452.

115 Hashimoto, S.I., Sakamoto, H., Honda, T., Abe, H., Nakamura, S.I. and Ikegami, S. (1997) Tetrahedron Letters, 38, 89698972.

116 Wulff, G. and Rohle, G. (1974) Angewandte Chemie (International Edition in English), 13, 157-170.

117 Demchenko, A., Stauch, T. and Boons, G. J. (1997) Synlett, 818-820.

118 Fukase, K., Hasuoka, A., Kinoshita, I., Aoki, Y. and Kusumoto, S. (1995) Tetrahedron, 51, 4923-4932.

119 Hashimoto, S., Hayashi, M. and Noyori, R. (1984) Tetrahedron Letters, 25, 13791382.

120 Manabe, S., Ito, Y. and Ogawa, T. (1998) Synlett, 628-630. 
121 Uchiro, H. and Mukaiyama, T. (1996) Chemistry Letters, 271-272.

122 Veeneman, G.H., van Leeuwen, S.H. and van Boom, J.H. (1990) Tetrahedron Letters, 31, 1331-1334.

123 Veeneman, G.H. and van Boom, J.H. (1990) Tetrahedron Letters, 31, 275-278.

124 Mukaiyama, T. and Matsubara, K. (1992) Chemistry Letters, 1041-1044.

125 Klimov, E.M., Malysheva, N.N., Demchenko, A.V., Makarova, Z.G., Zhulin, V.M. and Kochetkov, N.K. (1989) Doklady Akademii Nauk, 309, 110-114, and references therein.

126 Sasaki, M., Gama, Y., Yasumoto, M. and Ishigami, Y. (1990) Tetrahedron Letters, 31, 6549-6552.

127 Wegmann, B. and Schmidt, R.R. (1987) Journal of Carbohydrate Chemistry, $\mathbf{6}$, 357-375.

128 Nishizawa, M., Shimomoto, W., Momii, F. and Yamada, H. (1992) Tetrahedron Letters, 33, 1907-1908.

129 Shimizu, H., Ito, Y. and Ogawa, T. (1994) Synlett, 535-536.

130 Chenault, H.K., Castro, A., Chafin, L.F. and Yang, J. (1996) Journal of Organic Chemistry, 61, 5024-5031.

131 Schmidt, R.R. and Rucker, E. (1980) Tetrahedron Letters, 21, 1421-1424.

132 Dohi, H., Nishida, Y., Tanaka, H. and Kobayashi, K. (2001) Synlett, 1446-1448.

133 Spijker, N.M. and van Boeckel, C.A.A. (1991) Angewandte Chemie (International Edition in English), 30, 180-183.

134 Dwek, R.A. (1996) Chemical Reviews, 96, 683-720.

135 Herzner, H., Reipen, T., Schultz, M. and Kunz, H. (2000) Chemical Reviews, 100, 4495-4537.

136 Rai, R., McAlexander, I. and Chang, C.W. T. (2005) Organic Preparations and Procedures International, 37, 337-375.

137 Casu, B. (1985) Advances in Carbohydrate Chemistry and Biochemistry, 43, 51-134.

138 Varki, A. (1993) Glycobiology, 3, 97-130.

139 Varki, A., Cummings, R., Esko, J., Freeze, H., Hart, G. and Marth, J. (1999) Essentials of Glycobiology, Cold Spring Harbor
Laboratory Press, Cold Spring Harbor, NY.

140 Banoub, J., Boullanger, P. and Lafont, D. (1992) Chemical Reviews, 92, 1167-1195.

141 Debenham, J., Rodebaugh, R. and FraserReid, B. (1997) Liebigs Annalen-Recueil, 791-802.

142 Bongat, A.F.G. and Demchenko, A.V. (2007) Carbohydrate Research, 342, 374-406.

143 Boons, G.J. and Demchenko, A.V. (2000) Chemical Reviews, 100, 4539-4565.

144 Kiso, M., Ishida, H. and Ito, H. (2000) Carbohydrates in Chemistry and Biology, vol. 1 (eds B. Ernst, G.W. Hart and P. Sinay), Wiley-VCH Verlag $\mathrm{GmbH}$, Weinheim, New York, pp. 345-366.

145 von Itzstein, M. and Thomson, R.J. (1997) Topics in Current Chemistry, 186, 119-170.

146 Ress, D.K. and Linhardt, R.J. (2004) Current Organic Synthesis, 1, 31-46.

147 De Meo, C. (2007) American Chemical Society Symposium Series, 960, 118-131.

148 Okamoto, K., Kondo, T. and Goto, T. (1987) Bulletin of the Chemical Society of Japan, 60, 631-636.

149 Veyrieres, A. (2000) Carbohydrates in Chemistry and Biology, vol. 1 (eds B. Ernst, G.W. Hart and P. Sinay), Wiley-VCH Verlag GmbH, Weinheim, New York, pp. 367-406.

150 Marzabadi, C.H. and Franck, R.W. (2000) Tetrahedron, 56, 8385-8417.

151 El Ashry, E.S.H., Rashed, N. and Ibrahim, E.S.I. (2005) Current Organic Synthesis, 2, 175-213.

152 Crich, D. (2002) Journal of Carbohydrate Chemistry, 21, 667-690.

153 Ito, Y. and Ohnishi, Y. (2001) Glycoscience: Chemistry and Chemical Biology, vol. 2 (eds B. Fraser-Reid, K. Tatsuta and J. Thiem), Springer, Berlin, Heidelberg, New York, pp. 1589-1620.

154 Gridley, J.J. and Osborn, H.M.I. (2000) Journal of the Chemical Society Perkin Transactions, 1, 1471-1491.

155 Pozsgay, V. (2000) Carbohydrates in Chemistry and Biology, vol. 1 (eds B. Ernst, G.W. Hart and P. Sinay),Wiley-VCH 
Verlag GmbH, Weinheim, New York, pp. 319-343.

156 Gelin, M., Ferrieres, V. and Plusquellec, D. (2000) European Journal of Organic Chemistry, 1423-1431.

157 Lowary, T.L. (2002) Journal of Carbohydrate Chemistry, 21, 691-722.

158 Mukaiyama, T., Hashimoto, Y. and Shoda, S. (1983) Chemistry Letters, 935-938.

159 Gelin, M., Ferrières, V. and Plusquellec, D. (1997) Carbohydrate Letters, 2, 381-388.

160 Yin, H., D'Souza, F.W. and Lowary, T.L. (2002) Journal of Organic Chemistry, 67, 892-903.

161 Bogusiak, J. and Szeja, W. (2001) Carbohydrate Research, 330, 141-144.

162 Gadikota, R.R., Callam, C.S. and Lowary, T.L. (2001) Organic Letters, 3, 607-610.

163 Marotte, K., Sanchez, S., Bamhaoud, T. and Prandi, J. (2003) European Journal of Organic Chemistry, 3587-3598.

164 Lee, Y.J., Lee, K., Jung, E.H., Jeon, H.B. and Kim, K.S. (2005) Organic Letters, 7, 3263-3266.

165 Gadikota, R.R., Callam, C.S. and Lowary, T.L. (2001) Organic Letters, 3, 607-610.

166 Gadikota, R.R., Callam, C.S., Wagner, T., Del Fraino, B. and Lowary, T.L. (2003) Journal of the American Chemical Society, 125, 4155-4165.

167 Callam, C.S., Gadikota, R.R., Krein, D.M. and Lowary, T.L. (2003) Journal of the American Chemical Society, 125, 1311213119.

168 Cociorva, O.M. and Lowary, T.L. (2004) Tetrahedron, 60, 1481-1489.

169 Bai, Y. and Lowary, T.L. (2006) Journal of Organic Chemistry, 71, 9658-9671.

170 Zhu, X.M., Kawatkar, S., Rao, Y. and Boons, G.J. (2006) Journal of the American Chemical Society, 128, 11948-11957.

171 Crich, D., Pedersen, C.M., Bowers, A.A. and Wink, D.J. (2007) Journal of Organic Chemistry, 72, 1553-1565.

172 Ishiwata, A., Akao, H. and Ito, Y. (2006) Organic Letters, 8, 5525-5528.

173 Koto, S., Uchida, T. and Zen, S. (1973) Bulletin of the Chemical Society of Japan, 46, 2520-2523.
174 Ogawa, T., Yamamoto, H., Nukada, T., Kitajima, T. and Sugimoto, M. (1984) Pure and Applied Chemistry, 56, 779-795.

175 Demchenko, A.V. (2005) Letters in Organic Chemistry, 2, 580-589.

176 Nicolaou, K.C., Dolle, R.E., Papahatjis, D. P. and Randall, J.L. (1984) Journal of the American Chemical Society, 106, 41894192.

177 Lonn, H. (1985) Carbohydrate Research, 139, 105-113.

178 Garegg, P.J. and Oscarson, S. (1985) Carbohydrate Research, 136, 207-213.

179 Fugedi, P., Garegg, P.J., Lonn, H. and Norberg, T. (1987) Glycoconjugate Journal, 4, 97-108.

180 Baeschlin, D.K., Chaperon, A.R., Charbonneau, V., Green, L.G., Ley, S.V., Lucking, U. and Walther, E. (1998) Angewandte Chemie (International Edition), 37, 3423-3428.

181 Demchenko, A.V., Kamat, M.N. and De Meo, C. (2003) Synlett, 1287-1290.

182 Pornsuriyasak, P. and Demchenko, A.V. (2005) Tetrahedron: Asymmetry, 16, 433439.

183 Tanaka, H., Adachi, M., Tsukamoto, H., Ikeda, T., Yamada, H. and Takahashi, T. (2002) Organic Letters, 4, 4213-4216.

184 Kanie, O., Ito, Y. and Ogawa, T. (1994) Journal of the American Chemical Society, 116, 12073-12074.

185 Kanie, O. (2000) Carbohydrates in Chemistry and Biology, vol. 1 (eds B. Ernst, G.W. Hart and P. Sinay),Wiley-VCH Verlag GmbH, Weinheim, New York, pp. 407-426.

186 Ito, Y., Kanie, O. and Ogawa, T. (1996) Angewandte Chemie (International Edition), 35, 2510-2512.

187 Ferguson, J. and Marzabadi, C. (2003) Tetrahedron Letters, 44, 3573-3577.

188 Pornsuriyasak, P. and Demchenko, A.V. (2006) Chemistry - A European Journal, 12, 6630-6646.

189 Yamada, H., Harada, T., Miyazaki, K. and Takahashi, T. (1994) Tetrahedron Letters, 35, 3979-3982. 
190 Yamada, H., Harada, T. and Takahashi, T. (1994) Journal of the American Chemical Society, 116, 7919-7920.

191 Mukaiyama, T., Ikegai, K., Jona, H., Hashihayata, T. and Takeuchi, K. (2001) Chemistry Letters, 840-841.

192 Nicolaou, K.C., Caulfield, T., Kataoka, H. and Kumazawa, T. (1988) Journal of the American Chemical Society, 110, 79107912.

193 Fraser-Reid, B., Udodong, U.E., Wu, Z.F., Ottosson, H., Merritt, J.R., Rao, C.S., Roberts, C. and Madsen, R. (1992) Synlett, 927-942, and references therein.

194 Yamago, S., Yamada, T., Hara, O., Ito, H., Mino, Y. and Yoshida, J. (2001) Organic Letters, 3, 3867-3870.

195 Danishefsky, S.J. and Bilodeau, M.T. (1996) Angewandte Chemie (International Edition in English), 35, 1380-1419.

196 Deshpande, P.P., Kim, H.M., Zatorski, A., Park, T.K., Ragupathi, G., Livingston, P.O., Live, D. and Danishefsky, S.J. (1998) Journal of the American Chemical Society, 120, 1600-1614.

197 Huang, X., Huang, L., Wang, H. and Ye, X.S. (2004) Angewandte Chemie (International Edition), 43, 5221-5224.
198 Wang, Y., Yan, Q., Wu, J., Zhang, L.H. and Ye, X.S. (2005) Tetrahedron, 61, 43134321.

199 Roy, R., Andersson, F.O. and Letellier, M. (1992) Tetrahedron Letters, 33, 6053-6056.

200 Cao, S., Hernandez-Mateo, F. and Roy, R. (1998) Journal of Carbohydrate Chemistry, 17, 609-631.

201 Huang, L., Wang, Z. and Huang, X. (2004) Chemical Communications, 1960-1961.

202 Mootoo, D.R., Konradsson, P., Udodong, U. and Fraser-Reid, B. (1988) Journal of the American Chemical Society, 110, 55835584.

203 Douglas, N.L., Ley, S.V., Lucking, U. and Warriner, S.L. (1998) Journal of the Chemical Society Perkin Transactions, 1, 51-65.

204 Zhang, Z., Ollmann, I.R., Ye, X.S., Wischnat, R., Baasov, T. and Wong, C.H. (1999) Journal of the American Chemical Society, 121, 734-753.

205 Kamat, M.N. and Demchenko, A.V. (2005) Organic Letters, 7, 3215-3218.

206 Smoot, J.T., Pornsuriyasak, P. and Demchenko, A.V. (2005) Angewandte Chemie (International Edition), 44, 7123-7126. 
